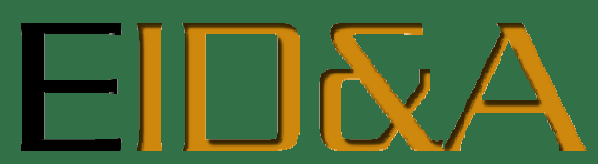

Revista Eletrônica de Estudos Integrados em Discurso e Argumentação

http://dx.doi.org/10.17648/eidea-12-1091

\title{
PEDALADAS FISCAIS: DISCURSOS DO JORNAL O ESTADO DE SÃO PAULO
}

\section{Livia Dias de Azevedo ${ }^{\mathrm{i}}$}

Resumo: Este artigo apresenta uma reflexão a respeito do ponto de tensão formado por meio dos discursos de duas reportagens do Jornal O Estado de São Paulo, popularmente conhecido como Estadão, sobre as pedaladas fiscais. Esses diferentes discursos constroem realidades que reforçam ou refutam a necessidade de impeachment da presidente Dilma Rousseff. Para analisar os textos do jornal, utilizaram-se principalmente Pêcheux (2008), Brandão (2012), Orlandi (2015), Maingueneau (2015), dentre outros, como principais referências teóricas e metodológicas em Análise do Discurso. É possível observar, com base na análise realizada, que a linguagem presente nos textos do jornal não é transparente, objetiva e autoexplicativa. A linguagem está na fronteira, no cruzamento, no entre-lugar do dito e não dito, das intenções que refletem as ideologias, refletem também vontades, desejos e posicionamentos. É por meio da linguagem que os efeitos de sentido vão sendo construídos e reconstruídos, num jogo de mostrar e esconder para convencer.

Palavras-chave: Análise do Discurso. Condições de produção. Jornal. Pedaladas fiscais.

\begin{abstract}
This paper presents a reflection on the tension point formed by the discourses conveyed by the newspaper O Estado de São Paulo on "fiscal pedaling". These different discourses construct realities that reinforce or refute the need for the impeachment of President Dilma Rousseff. To analyze the newspaper's texts, we drew upon Pêcheux (2008), Brandão (2012), Orlandi (2015), Maingueneau (2015), among others, as the main theoretical and methodological references in Discourse Analysis. It is possible to see, through the performed analysis, that the language in the newspaper's texts is not transparent, objective and self-explanatory. Language is at the boundary, at the crossroads, at the in-between of the said and the unsaid, of the intentions that reflect ideologies, also reflecting wills, desires and stances. It is through language that the effects of meaning are being built and rebuilt, in a game of showing and hiding to convince.
\end{abstract}

Keywords: Discourse analysis. Conditions of production. Newspaper. Fiscal pedaling.

i Doutoranda em Ensino e História das Ciências da Terra pela Universidade Estadual de Campinas (UNICAMP). Professora Assistente da Universidade Estadual de Feira de Santana (UEFS). E-mail: liviadias2@gmail.com. 
EID\&A - Revista Eletrônica de Estudos Integrados em Discurso e Argumentação, Ilhéus, n. 12, jul/dez.2016.

\section{Introdução}

Em sete de outubro de 2015, o Tribunal de Contas da União (TCU) rejeitou/desaprovou a execução do orçamento de 2014 do governo da presidente Dilma Rousseff. Este acontecimento foi suficiente para movimentar o mundo político e econômico do Brasil. Daí em diante, as contas do governo federal ganharam todos os holofotes das mídias impressas, televisivas, radiofônicas e virtuais do país. Nas redes sociais, como o Instagram, o Twitter e o Facebook, esse tema também virou pauta permanente e um termo já há algum tempo esquecido é recuperado: as chamadas pedaladas fiscais. Muitos jornais impressos e televisivos consultaram diversos especialistas em finanças, economia e direito para explicar, a partir de seus pontos de vistas, as pedaladas fiscais.

O discurso político, o econômico e o jurídico operaram análises que ora se aproximam e ora se afastam da discussão em torno das pedaladas fiscais. Esses diferentes discursos constroem realidades que reforçam ou refutam a necessidade do impeachment. É importante destacar que esses discursos (político, econômico e jurídico) estabelecem diálogos entre si, um permeia e atravessa o outro, formando uma rede cambiante e contingente de enunciados.

Segundo o website Jusbrasil ${ }^{1}$, as pedaladas fiscais são débitos contraídos pelo governo junto a bancos públicos. No caso das pedaladas fiscais em questão, essas se referem aos débitos contraídos pelo governo federal junto à Caixa Econômica Federal, ao Banco do Brasil e ao Banco Nacional do Desenvolvimento Econômico e Social (BNDES), basicamente para pagamentos de programas sociais mantidos pelo governo federal. De forma menos complexa, a questão funciona da seguinte forma: a Caixa Econômica Federal, banco público que mantém contrato de pagamentos de programas sociais do governo federal, paga à população seguro desemprego e bolsa família, dentre outros programas, e o fundo de garantia. Esse dinheiro deve ser devolvido à Caixa por meio de depósito, e quando isso não ocorre o governo contrai uma dívida com o banco, ficando com saldo negativo em sua conta até que seja efetuado um novo depósito que cubra o débito contraído.

É necessário, dessa forma, que exista um equilíbrio financeiro entre os valores que são pagos pelo banco e os valores que são depositados pelo

\footnotetext{
${ }^{1}$ Disponível em: http://mercadopopular.jusbrasil.com.br/artigos/241550408/o-que-e-pedalada-fiscalum-manual-para-nao-economistas. Acesso em: 20 mai.2016.
} 
EID\&A - Revista Eletrônica de Estudos Integrados em Discurso e Argumentação, Ilhéus, n. 12, jul/dez.2016.

governo. Quando o débito se prolonga por um período de tempo extenso ou quando há acúmulo de débitos, ou seja, o banco paga várias vezes sem a devida reposição, acontecem as pedaladas fiscais. Esse sistema é orientado pela Lei de Responsabilidade Fiscal, oficialmente: Lei complementar $\mathrm{N}^{\circ} 101$ de 04 de maio de 2000.

Tomando por base o cenário descrito acima, os debates sobre as pedaladas fiscais estão na ordem do dia, assim, o presente texto pretende analisar os discursos de duas reportagens do Jornal O Estado de São Paulo, popularmente conhecido como Estadão. Essas duas reportagens: a primeira, "Dilma planejou milimetricamente seus crimes de responsabilidade", escrita por Luísa Martins e Gustavo Porto, em 11.05.2016, e a segunda "Instituições democráticas perdem para democracia da maioria", escrita por Wagner Romão, em 12.05.2016, foram escolhidas em função dos seus posicionamentos. A primeira argumenta que as "pedaladas" constituem crime de responsabilidade fiscal, a segunda que não constituem crime de responsabilidade, por consequência, são, respectivamente, favorável e contrária ao impeachment da presidente Dilma Rousseff. Vale ressaltar que os posicionamentos favoráveis ao impeachment veem nas pedaladas fiscais o motivo principal para impedir a continuidade do governo da presidente Dilma. Isso constitui um ponto de tensão, uma vez que os opositores ao governo consideram as "pedaladas" um crime de responsabilidade fiscal e, portanto, passível de pedido de impeachment; enquanto que os aliados à presidente consideram que as "pedaladas" não constituem o referido crime. Assim, para o desenvolvimento das análises aqui propostas, foram utilizados como referência postulados de autores como Pêcheux (2008) e Maingueneau (2015), os quais filiam-se à linha francesa da Análise do discurso (AD). Dessa forma, ao analisar os enunciados constantes no jornal, visa-se indicar as posições assumidas, ideologias e formações discursivas a partir das quais os sujeitos falam. 
EID\&A - Revista Eletrônica de Estudos Integrados em Discurso e Argumentação, Ilhéus, n. 12, jul/dez.2016.

\section{Tateando ${ }^{2}$ o discurso}

O termo discurso é de uso corrente no cotidiano das pessoas, utilizado, basicamente, para designar uma fala, uma enunciação. Evidentemente, para os autores e pesquisadores da $A D$, o discurso é definido de forma mais complexa, mas não se nega o uso comum do termo, talvez ao contrário, se utiliza de fragmentos desse uso comum, afinal é na língua que o discurso ganha materialidade (POSSENTI, 2009; ORLANDI, 2015).

Para Possenti (2009, p. 16), o discurso é "um efeito de sentido, uma posição, uma ideologia - que se materializa na língua, embora não mantenha uma relação biunívoca com recursos de expressão da língua". Ou seja, é por meio do texto falado e escrito que a discursividade toma forma, conteúdo e posição. Os textos (falado e escrito) materializam discursos que são formados dentro de formações discursivas distintas, embora os discursos passeiem pelas formações discursivas. Os efeitos de sentidos produzidos pelos discursos estão colados à posição do sujeito (locutor e ouvinte) e às condições de produção $(C D)$ do próprio discurso. $O$ sujeito que reproduz um discurso o faz a partir de certa posição (social, política, econômica, religiosa, dentre outras), ou ainda, da formação discursiva e ideológica da qual faz parte. Esta é uma relação de mão-dupla: posição do sujeito e formação discursiva, uma é constitutiva da outra.

Nesse sentido, Orlandi (2015, p. 13-14) esclarece que a AD não trabalha a linguagem como sistema abstrato, mas com a língua enquanto materialidade simbólica, "com maneiras de significar, com homens falando, considerando a produção de sentidos enquanto parte de suas vidas, seja enquanto sujeitos, seja enquanto membros de uma determinada forma de sociedade".

Dominique Maingueneau (2015), por sua vez, defende que para falar de discurso é preciso mobilizar o que chama de ideias-forças ${ }^{3}$, que são, de forma superficial, ideias que dão fôlego e potência ao conceito de discurso, são ideias que forçam a pensar o discurso para além da linguística, no conjunto da própria realidade social. É como se as ideias-forças aproximassem o discurso da própria vida. Desse modo, o referido autor explica que

\footnotetext{
2Esse termo é emprestado de Eni Orlandi que na introdução do livro "A inquietação do discurso", de Denise Maldidier. Orlandi (2003, p. 10) utiliza o termo "tatear" para dizer que "não há uma teoria já pronta que sirva de instrumento para a análise". É, nesse sentido, que o termo é utilizado neste texto, como possibilidade de construção de conceitos e análises que vão se constituindo e se impondo à medida que a analista lê as teorias específicas da Análise do Discurso e organiza o corpus proposto.

${ }^{3}$ Sobre as ideias-forças ver Maingueneau (2015, p. 25-33).
} 
EID\&A - Revista Eletrônica de Estudos Integrados em Discurso e Argumentação, Ilhéus, n. 12, jul/dez.2016.

[...] o sentido de que trata aqui não é um sentido diretamente acessível, estável, imanente a um enunciado ou a um grupo de enunciados que estaria esperando para ser decifrado: ele é continuamente construído e reconstruído no interior de práticas sociais determinadas. Essa construção do sentido é, certamente, obra de indivíduos, mas de indivíduos inseridos em configurações sociais de diversos níveis (MAINGUENEAU, 2015, p. 29).

Dessa maneira, o sentido se constrói à medida que a sociedade se movimenta. Assim, o sentido é temporariamente estável, visto que o movimento social, econômico, cultural, também o é. A história não é fixa. A sociedade muda, transforma, reelabora, ressignifica os sentidos dos acontecimentos.

Possenti (2009, p. 16) explica ainda que "embora sempre haja um 'suporte' linguístico para um discurso, nem sempre o mesmo recurso da língua 'expressa' o mesmo discurso, ou seja, aceita a mesma interpretação”. Essa noção para o presente texto é central, justamente-porque, nesse caso, a ideia de crime e a ideia de não crime decorrem do mesmo fato: as pedaladas fiscais. Isso quer dizer que o tema em questão é significado de maneiras distintas por sujeitos distintos.

\section{Tateando as condições de produção}

As condições de produção (CP) constituem um dos conceitos-chave dos estudos em AD. É a partir das CP que os discursos emergem e circulam por diversos lugares e tempos. Aliás, é da relação espaço-tempo-sociedade que as CP são criadas. Foucault (2005) explica que as CP são situações únicas que produzem discursos únicos e que essas muito dificilmente poderão se repetir. Para o autor, as CP são porosidades, são rupturas na história linear, cronológica, que produzem acontecimentos de diversas escalas espaciais, temporais e de múltiplas capacidades para produzir efeitos de sentidos. Nessa perspectiva, a respeito dos acontecimentos, Foucault (2005) analisa que:

\footnotetext{
A história serial permite de qualquer forma fazer aparecer diferentes estratos de acontecimentos dos quais uns são visíveis, imediatamente conhecidos até pelos contemporâneos, e em seguida, debaixo desses acontecimentos que são de qualquer forma a espuma da história, há outros acontecimentos invisíveis, imperceptíveis para os contemporâneos, e que são de um tipo completamente diferente [...]. Por baixo desse estrato de acontecimentos, existe outro tipo de acontecimentos um pouco mais difusos (FOUCAULT, 2005, p. 291).
} 
EID\&A - Revista Eletrônica de Estudos Integrados em Discurso e Argumentação, Ilhéus, n. 12, jul/dez.2016.

Foucault salienta que existem muitos e variados tipos de acontecimentos - há camadas de acontecimentos, uns visíveis, outros invisíveis - mas que esses só são apreendidos com a consulta aos arquivos, às coleções, enfim, aos documentos históricos, que informam acerca dos os acontecimentos. Talvez seja importante salientar que os acontecimentos, embora postos sobre camadas, não possuem uma linearidade, ao contrário, são descontínuos e difusos. Daí decorre também a multiplicidade de enlaces possíveis, e o pesquisador, seja historiador, linguista ou analista do discurso, é quem decide quais acontecimentos serão unidos, conectados para realizar suas análises e reflexões.

Na AD, os postulados de Pêcheux e Foucault ora se aproximam ora se afastam. Na discussão sobre as $C P$, para que se possa pensar o funcionamento da língua na história, a noção de história serial desenvolvida por Foucault é basilar, porque, assim como são as porosidades da história, são também as porosidades na língua, suas brechas, falhas e descontinuidades.

Um exemplo que cabe retomar para este texto são as condições políticas, financeiras, culturais, tecnológicas que, em 1992, culminaram no pedido de impeachment do então presidente Fernando Collor de Melo. É possível perceber que as condições que desencadearam o pedido de impeachment da atual presidente Dilma Rousseff são outras. Embora seja o mesmo procedimento político e jurídico, as CD do pedido de impeachment nos dois casos são bem distintas. Assim como são diferentes o contexto de realização e o julgamento das pedaladas fiscais.

É esse processo de transformação que possibilita o aparecimento dos discursos, e são os mecanismos, as condições sociais, históricas e geográficas que possibilitam a emergência dos discursos. Por exemplo, é preciso levar em consideração as condições que promoveram a necessidade de realização das pedaladas fiscais, bem como as condições que as colocam como crime de responsabilidade, já que esta é/era uma prática comum empreendida por presidentes, governadores e prefeitos brasileiros.

Quanto às $C P$, Courtine assinala que:

[...] essas formulações ("características individuais de um enunciado", "situações interpessoais") designam o que a Linguística conhece como sujeito da enunciação e situação de enunciação. [...] Quanto ao trabalho de Harris, talvez tivesse sido melhor caracterizá-lo como origem "espontânea" ou "involuntária" da noção de CP, no sentido em que a representação do exterior 
EID\&A - Revista Eletrônica de Estudos Integrados em Discurso e Argumentação, Ilhéus, n. 12, jul/dez.2016.

do objeto linguístico inscreve-se "espontaneamente" na caracterização psicossocial de uma situação de comunicação (COURTINE, 2009, p. 47).

Isso quer dizer que as condições externas ou extralinguísticas interessam à $A D$ na medida em que explicam a emergência dos enunciados e a posição social do sujeito da enunciação. As CP produzem discursos que mantêm relação com determinadas formações ideológicas. Essas CP estão situadas em um tempo e espaço específicos, sobretudo, porque a história não se realiza no vazio, as relações sociais ocorrem no espaço e são por ele influenciadas, condicionadas. Vale destacar que as CP sempre são condições históricas de formulação do discurso: é o caminhar histórico que constrói as CP. Para Brandão (2012, p. 45), Courtine "postula uma redefinição da noção de $\mathrm{CP}$ alinhada à análise histórica das contradições ideológicas presentes na materialidade dos discursos e articulada teoricamente com o conceito de formação discursiva".

Na esteira de Courtine, Orlandi (2015, p. 28-29) compreende que, assim como o sujeito e a situação, também a memória faz parte da produção do discurso. A maneira como a memória é acionada faz valer as condições de produção. Em sentido estrito, temos as circunstâncias da enunciação: é o contexto imediato; em sentido amplo, são incluídos o contexto sóciohistórico, ideológico e o geográfico.

Nas reportagens do Jornal Estadão analisadas neste texto, a linguagem nos permite entender de qual posição social o sujeito comentarista fala. $O$ léxico que o enunciador utiliza indica seu posicionamento contra ou a favor das pedaladas fiscais e seu entendimento favorável ou contrário ao crime de responsabilidade fiscal. A esse respeito, Brandão (2012) reforça que a linguagem enquanto discurso é interação entre sujeitos e é, dessa forma, produção social. Segundo Brandão (2012, p. 11), "a linguagem é lugar de conflito, de confronto ideológico, não podendo ser estudada fora da sociedade [...]. Seu estudo não pode estar desvinculado de suas condições de produção". As CP indicam o contexto situacional de produção dos discursos, mas são as formações discursivas que definem de que lugar o sujeito fala, enuncia.

\section{0 corpus}

O Estadão é referência em informação no Brasil, especialmente em São Paulo. Este jornal foi escolhido como documento de análise por dois motivos 
EID\&A - Revista Eletrônica de Estudos Integrados em Discurso e Argumentação, Ilhéus, n. 12, jul/dez.2016.

principais: o primeiro se refere a sua abrangência em nível nacional, uma vez que ele possui rádio e está nas principais redes sociais, tais como Instagram, Facebook e Twitter; segundo, porque recebe importantes patrocínios, o que confirma sua relevância no cenário jornalístico brasileiro. São patrocinadores do Estadão: o banco Bradesco, a Omo, a IBM, entre outros. O jornal conta ainda com anunciantes como a Intel e a Jeep. Essas empresas oferecem serviços e produtos para pessoas de alto poder aquisitivo. A Omo, por exemplo, comercializa a marca de sabão em pó mais cara dos supermercados do Brasil, basta uma consulta rápida nos folhetos de supermercado disponíveis na internet.

Esse veículo de comunicação também oferece seu conteúdo em diversas plataformas, o acesso é possível por meio de computador ou notebook, é possível ler o jornal em celulares e tablets, e em diferentes sistemas operacionais, como o IOS, da Apple, e o Android, utilizado por vários fabricantes de celular, como a Samsung, Motorola e LG, por exemplo. O Estadão oferece um serviço de notícias em tempo real, o Broadcast Político do Estadão conteúdo. Esses elementos são indicadores de que o seu conteúdo é de fácil e amplo acesso, e seus patrocinadores e anunciantes são evidências de que o jornal em questão é destinado a um público de alto poder aquisitivo e com certa formação educacional. O Estadão prevê o seu público, efeito leitor ${ }^{4}$, e, assim, ajusta seu conteúdo para seu leitor e, desse modo, aos poucos, ajuda a formar representações provisórias a respeito dos acontecimentos. Nesse jogo, há uma dupla representação: a imaginária que o jornal faz do leitor/sujeito e a representação que esse leitor/sujeito faz dos textos que lê e das informações que circulam por estas textualizações.

O referido jornal tem, em seu quadro de colunistas, importantes nomes da política brasileira, como o ex-presidente Fernando Henrique Cardoso e o jornalista e comentarista político Arnaldo Jabor. As falas desses colunistas têm certo respeito entre os leitores, mesmo que sejam atravessadas por políticas partidárias ou anti-partidárias, por isso são considerados formadores de opinião.

O corpus deste trabalho se constitui de segmentos de duas reportagens do jornal Estadão que têm como mote as pedaladas fiscais, como foram denominadas pela grande mídia. O reconhecimento para o grande público como crime de responsabilidade fiscal ocorreu especialmente no período de

${ }^{4}$ Sobre efeito-leitor ver Pêcheux (2014) e Orlandi (2001, 1996). 
EID\&A - Revista Eletrônica de Estudos Integrados em Discurso e Argumentação, Ilhéus, n. 12, jul/dez.2016.

uma semana, mais exatamente, na semana de votação no Senado Federal pelo afastamento da presidente Dilma Rousseff. O conjunto de reportagens levantadas datam do dia 08.05.2016 ao dia 15.05.2016, semana de afastamento da presidente. A votação iniciou-se na quarta-feira do dia 11.05 .16 e foi encerrada no dia 12.05.16, após vinte horas de exposição de argumentos contra e a favor e de votação aberta dos senadores, pela permanência ou pelo afastamento da presidente. Desse conjunto de reportagens levantadas, consultadas, organizadas e selecionadas, como anunciado, duas reportagens foram escolhidas: a primeira, publicada no dia 11.05.16, sob título "Dilma planejou milimetricamente seus crimes de responsabilidade", escrita por Luísa Martins e Gustavo Porto, e a segunda, publicada no dia 12.05.16, "Instituições democráticas perdem para democracia da maioria”, escrita por Wagner Romão.

É importante dizer que a escolha do período das reportagens selecionadas para a presente análise centrou-se nas datas de início e final da votação do impeachment no Senado, devido ao número significativo de textos que tratavam de forma direta e indireta do tema aqui proposto: as pedaladas fiscais. Ao colocar no buscador do website do Jornal Estadão as palavras "pedaladas fiscais", aparecem 1.323 registros. Quando as mesmas palavras são colocadas no buscador do Google aparecem 514 mil registros, isso indica a relevância do tema, sendo que a primeira reportagem indicada por esse buscador é, justamente, uma do jornal Estadão.

\section{Pedaladas fiscais: Discursos em movimento}

De acordo com Brandão (2012), não importa à AD qual indivíduo fala, mas de que lugar social este sujeito fala. No caso do jornal Estadão, por exemplo, cada blogueiro, colunista e jornalista assina seus textos, mas estes textos viram discursos do jornal, isto porque se o jornal veicula esses textos os toma como de sua responsabilidade.

Embora dentro da estrutura do jornal cada uma dessas categorias (blogueiro, colunista, jornalista) ocupe um lugar privilegiado, elas também mantêm certo destaque dentro da sociedade, na medida em que a escolha dos profissionais que assinam os textos do jornal não se dá de forma aleatória. A escolha pode ocorrer não necessariamente porque um profissional seja especialista na matéria, mas porque ocupa um lugar de destaque no cenário nacional. Esses textos refletem a posição social, política, econômica e cultural 
EID\&A - Revista Eletrônica de Estudos Integrados em Discurso e Argumentação, Ilhéus, n. 12, jul/dez.2016.

de cada autor, refletem suas ideologias e a formação imaginária que cada um tem de si e dos leitores do jornal.

A esse respeito, Brandão (2012, p. 44) explica que "em todo processo discursivo, o emissor pode antecipar as representações do receptor e, de acordo com essa antevisão do "imaginário" do outro, fundar estratégias de discurso". É o que se observa nos textos dos jornais Estadão: a construção contínua de representações acerca das pedaladas fiscais. Essas representações construídas pelo jornal podem, inclusive, fazer com que o sujeito/leitor mude de opinião a respeito de um tema ou problemática. O texto sempre contém uma posição, uma intenção, um olhar específico. As estratégias de discurso são expressas, principalmente, por meio do léxico utilizado pelos sujeitos, pois é no jogo da linguagem que as estratégias vão sendo alinhadas.

Mas, no conjunto das reportagens organizadas, os textos do Estadão sobre as pedaladas fiscais tratam basicamente: a) do governo enquanto instituição; b) da lei de responsabilidade fiscal (que se aproxima do discurso jurídico); c) de crime; d) constituição; e) do impeachment. Desse modo, o discurso do jornal sobre a crise se estabelece a partir de três pilares: o político, o jurídico e o econômico. Vale notar que as pedaladas fiscais foram chamadas de crime, golpe, cheque especial, rombo e pecado, por exemplo. Como todos esses adjetivos têm conotação negativa, reforçam a ideia de crime. As palavras usadas pelos colunistas, jornalistas e blogueiros são indicadores da posição da qual falam, são indícios da posição favorável ou não ao afastamento da presidente e de que maneira julgam as pedaladas, como subsidiadora do afastamento. Já, outros irão dizer que as pedaladas fiscais se constituem em um procedimento periódico e, por isso, não justificaria o afastamento. Para esses, os adjetivos utilizados para as pedaladas são: golpe, necessidade, urgência, programas sociais, jurisprudência, entre outros. Desse modo, observa-se que as palavras mudam de conotação: agora são positivas. De fato, é um tema controverso. A palavra "golpe" é recorrente e usada pelos dois grupos, cada um deles usando-a à sua maneira. Nesse sentido, Pêcheux, Haroche e Henry (2008, p. 27) explicam que:

[...] o ponto essencial aqui é que não se trata apenas da natureza das palavras empregadas, mas também (e sobretudo) de construções nas quais essas palavras se combinam, na medida em que determinam a significação que tomam essas palavras: como apontávamos no começo, as palavras mudam de sentido segundo as posições ocupadas por aqueles que as empregam. Podemos agora 
EID\&A - Revista Eletrônica de Estudos Integrados em Discurso e Argumentação, Ilhéus, n. 12, jul/dez.2016.

deixar claro: as palavras, mudam de sentido" ao passar de uma formação discursiva a outra (grifos dos autores).

Observa-se, de acordo com Pêcheux, Haroche e Henry (2008, p. 26), que o sentido de uma palavra é determinado pelo lugar social e ideológico dos sujeitos que as empregam. Os significados são produzidos de acordo com as formações discursivas e ideológicas nas quais os sujeitos estão inseridos.

Há, pois, os que defendem as pedaladas fiscais como procedimento já instituído na prática de governos e outros que as defendem como crime de responsabilidade fiscal. Os que são contrários ao afastamento da presidente recorrem à memória para justificar que a prática em questão já foi utilizada por outros presidentes da república, como, por exemplo, Fernando Henrique Cardoso e Luís Inácio Lula da Silva, na época de suas gestões. Portanto, o afastamento da presidente Dilma Rousseff não teria justificativa.

Para se ter uma ideia da força da temática, apenas no dia 13.05.2016, foram publicadas no website do jornal cinco reportagens que envolviam as pedaladas fiscais. O dia do início da votação na Câmara dos Senadores, dia 12.05.2016, rendeu dezessete reportagens do jornal, passando por três editorias: geral, opinião e política. Dessas dezessete reportagens, catorze estão alocadas na editoria política. No dia anterior à votação, foram vinte reportagens, nas editorias de economia, política, vida e estilo, e opinião, sendo que quinze estão na editoria política do jornal. Como mencionado anteriormente, duas reportagens de $O$ Estado de São Paulo serão analisadas neste trabalho para discutir a polarização encontrada nos textos publicados nesse jornal, a primeira, "Dilma planejou milimetricamente seus crimes de responsabilidade" e a segunda, "Instituições democráticas perdem para democracia da maioria".

\section{1 "Dilma planejou milimetricamente seus crimes de responsabilidade"}

Das vinte reportagens do dia 11.05.16, chama atenção o seguinte enunciado, o qual é também título da primeira reportagem: "Dilma planejou milimetricamente seus crimes de responsabilidade" (Figura 1). Esse texto, que tem como título uma citação do senador Eduardo Amorim, é assinada por Luísa Martins e Gustavo Porto. Chama atenção, principalmente, o fato de o texto ser assinado por dois autores, um texto de apenas quatro parágrafos cuja metade é composta por citações do supracitado senador. Assim, há 
EID\&A - Revista Eletrônica de Estudos Integrados em Discurso e Argumentação, Ilhéus, n. 12, jul/dez.2016.

explicitamente quatro locutores diretamente implicados: os dois autores, o senador, e o editor da editoria política do jornal.

Figura 1 - Reportagem do Jornal O Estado de São Paulo

$\equiv$ ESTADÃO

$f \div \ldots Q$

\section{'Dilma planejou milimetricamente seus crimes de responsabilidade', diz Eduardo Amorim}

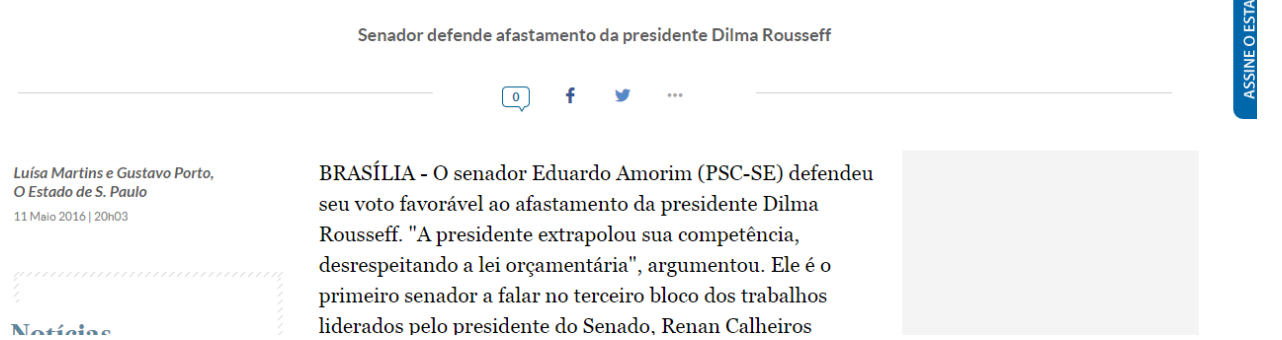

Fonte: Jornal O Estado de São Paulo em 11/05/2016.

No enunciado "Dilma planejou milimetricamente seus crimes" de responsabilidade", nota-se que a então presidente é colocada numa posição de criminosa experiente, que planeja com cuidado e acuidade os crimes que comete. Dilma perde, no enunciado, o título de presidente e se torna uma mulher criminosa, uma civil criminosa. Percebe-se que antecede ao nome da presidente apenas as aspas que destacam a frase do senador, evidenciando que o enunciado não levanta dúvidas ou questionamentos sobre a possibilidade de crime ou não, Dilma, logo, é sentenciada: culpada. Neste enunciado, a presidente já é considerada culpada, antes mesmo de ser julgada e condenada, pois sua condição de criminosa é estabelecida mesmo antes da votação no senado, votação que decidiria pelo afastamento (ou não) da presidente e não por qualquer tipo de absolvição. Afinal, não é um julgamento jurídico, o Congresso Nacional não tem essa especificidade. Logo, a partir da fala do senador Eduardo Amorim, sabe-se, antecipadamente, qual o seu voto e, dessa forma, qual a orientação de voto do partido/grupo político ao qual pertence. Embora não dito, os crimes de responsabilidade aos quais o senador se refere são a abertura de créditos suplementares e as pedaladas fiscais.

\footnotetext{
${ }^{5}$ Daqui em diante todos os grifos nos enunciados foram feitos pela autora desse texto, a fim de destacar algumas palavras que são importantes para a análise.
} 
EID\&A - Revista Eletrônica de Estudos Integrados em Discurso e Argumentação, Ilhéus, n. 12, jul/dez.2016.

Em outro enunciado, o senador declara: "Foi milimetricamente planejado. Essas práticas demonstram descaso para com a nossa constituição cidadã e para com as leis brasileiras, mostrando inequivocadamente o seu desapreço pelo Brasil”. Nesse trecho, fica explícita a opinião de que a presidente mantém uma relação de descaso com a constituição e as leis brasileiras, e subentendida a visão de que é uma governante que não se preocupa com o principal regimento brasileiro, a constituição. O senador utiliza o pronome "nossa" para falar da constituição, como se quisesse inserir os leitores, os brasileiros, a se mobilizarem, a se colocarem na situação, ou seja, há um descaso com o que é nosso, com o que é do cidadão brasileiro, dividindo o mundo político em nós, cidadãos, e a presidente, numa relação de opção bipolarizada. Agindo dessa forma, a presidente desconsidera as leis, e o cidadão brasileiro não é uma preocupação para ela. O senador não tem dúvidas de que a presidente não tem respeito, apreço, estima pelo Brasil, por isso age inequivocadamente. É uma presidente que não valoriza o próprio país que governa. É possível observar que as palavras de conotação negativa como descaso e desapreço são preponderantes na fala do senador e, consequentemente, na reportagem do jornal, que, de certa forma, chancela o senador.

Já sobre o vice-presidente Michel Temer, o enunciado é o seguinte: "ele precisará 'ser um maestro em busca do equilíbrio das contas públicas e da retomada do desenvolvimento". Veja que as palavras associadas ao vicepresidente nada têm de negativo, como as direcionadas à presidente Dilma (considerada criminosa). O vice-presidente será um condutor, atuando como um maestro, o qual ocupa um lugar de destaque em meio à orquestra que rege, estando esse título associado a uma figura erudita, culta, séria, que comanda com firmeza. Ao vice também cabe buscar o equilíbrio das contas públicas, desequilibradas pela presidente. Temer será o sujeito que organizará as contas e promoverá o desenvolvimento do país, é o comandante perfeito para administrar a nação. Maestro, equilíbrio e desenvolvimento são, então, palavras que dão uma conotação positiva a Temer. É possível inferir que, para valorizar o vice-presidente e sua capacidade de promover o desenvolvimento do país, é preciso desvalorizar, desqualificar, culpabilizar e criminalizar a presidente Dilma Rousseff, mesmo os dois políticos compondo a mesma chapa eleitoral na época da eleição presidencial em 2010 e 2014. 
EID\&A - Revista Eletrônica de Estudos Integrados em Discurso e Argumentação, Ilhéus, n. 12, jul/dez.2016.

Num terceiro enunciado "Ele disse que Dilma cometeu crime de responsabilidade, em função das chamadas pedaladas fiscais e dos créditos suplementares sem autorização do Congresso Nacional", nota-se, agora, que as mesmas "pedaladas", citadas anteriormente como crime, são amenizadas e atreladas a outra instância: o Congresso Nacional. Ou seja, se o senado aprovasse as pedaladas fiscais, elas deixariam de ser crime e estariam dentro dos procedimentos legais. Logo, o Congresso Nacional aprovaria um crime.

\section{2 "Instituições democráticas perdem para democracia da maioria"}

Das dezessete reportagens do dia 12.05.2016, uma chama atenção: "Instituições democráticas perdem para democracia da maioria", de autoria de Wagner Romão, um enunciado na segunda reportagem se destaca:

Dilma falhou nesse último quesito. Defendeu um programa na campanha e, ao chamar Levy para a Fazenda, tentou aplicar outro. Aécio e a oposição derrotada falharam no penúltimo quesito. Não respeitaram o resultado das eleições. Essa é a origem institucional da crise política pela qual passamos e que reforçou a crise da economia (grifos nossos).

Para Wagner Romão, autor que assina essa reportagem (Figura 2, a seguir), tanto Dilma quanto Aécio falharam e, assim, ambos são colocados na mesma posição. Observa-se que não há desvalorização de um em relação ao outro, os dois falharam, entretanto, em condições e por motivações distintas. O que fica subentendido é que foi o resultado das eleições que desencadeou a crise política entre a oposição e o governo, e isso repercutiu no agravamento da crise econômica. Não que a crise econômica não existisse, ela foi reforçada pela crise política instaurada. Nesse sentido, a ideia inicial de crime fica em segundo plano, visto que o motivo do afastamento da presidente Dilma é de ordem política e não, exatamente, jurídica.

No enunciado (texto 2), Romão explica que:

Dilma foi afastada não por aquilo do que foi acusada, mas por seus erros no campo da economia e da política. E sobretudo porque a parte hegemônica do sistema político brasileiro e isso inclui a grande maioria do Congresso e a cumplicidade dos ministros do Supremo Tribunal Federal assim o quis, ao arrepio das instituições políticas do País (grifos nossos).

Romão reforça a ideia de que o afastamento da presidente decorre de questões econômicas e políticas e não de crime contra a constituição. Segundo o autor da reportagem, Dilma teria sido afastada não pelas 
pedaladas fiscais, principal acusação imputada à presidente, mas, possivelmente, pela mobilização política que se formou em torno da figura de Dilma Rousseff. É possível identificar uma contradição no texto de Romão, na medida em que implica o Congresso e o Supremo Tribunal Federal como cúmplices na mobilização política de afastamento da presidente, o autor da reportagem constata que o afastamento acontece ao arrepio das instituições políticas do país. Mas, o Congresso e o Supremo Tribunal Federal são instituições políticas brasileiras e são os deputados, senadores e ministros que dão vida e sentido às instituições políticas. Os ministros não agem como pessoas do cotidiano, suas falas, posicionamentos e entendimentos representam uma instituição, a voz dos ministros é também a voz do Supremo Tribunal Federal. Dessa forma, as instituições políticas brasileiras também foram responsáveis pela movimentação política que culminara no afastamento da presidente. Pode não haver um consenso pleno, reconhecemse as lutas internas dentro das instituições, as contradições, discordâncias e protestos, mas o que se veicula como resposta à sociedade é a vontade da maioria, como no caso das votações na Câmara dos Deputados e a dos Senadores pelo afastamento.

Figura 2 - Reportagem do Jornal O Estado de São Paulo

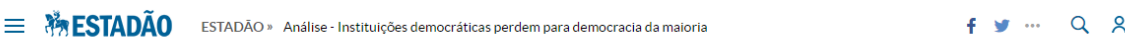

\section{Análise - Instituições democráticas perdem para democracia da maioria}

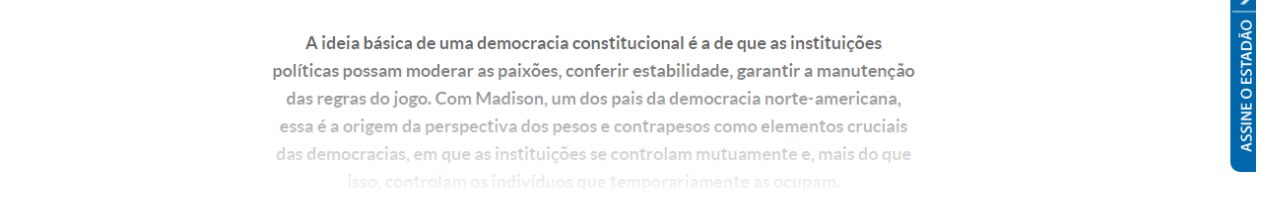

Para continuar lendo:

Tenha acesso a 14 textos

Aproveite todo conteúdo do Estadão

Fonte: Jornal O Estado de São Paulo, reportagem publicada em 12/05/2016. 
EID\&A - Revista Eletrônica de Estudos Integrados em Discurso e Argumentação, Ilhéus, n. 12, jul/dez.2016.

Em outro enunciado do texto 2, lemos:

Formou-se uma maioria contra a presidenta que ignorou os argumentos racionais da: 1) igualdade de condições para todos os gestores públicos: por que se condena apenas Dilma se muitos outros pedalaram em situações fiscais mais confortáveis?; e 2) da proporcionalidade da pena, pois mesmo que se aceite que Dilma desrespeitou as normas orçamentárias, isso não poderia se traduzir na pena máxima da perda de mandato (grifos nossos).

Esse enunciado é visivelmente favorável à permanência da presidente. Dilma, inclusive, é colocada numa posição de vítima, na medida em que uma maioria é formada contra ela, maioria que, segundo o autor, ignora argumentos lógicos, sensatos, contundentes.

Nesse enunciado (texto 2), os argumentos racionais se referem à igualdade e à proporcionalidade. Igualdade no sentido das pedaladas fiscais já terem sido feitas por outros governantes, ou seja, prática recorrente. Aqui não se fala de admissibilidade de crime, embora o termo condenar esteja presente na frase, mas esse condenar cria um sentido muito mais de vítima, de uma pessoa que está sendo culpabilizada por uma coletividade. O segundo argumento, o da proporcionalidade, é antagônico ao primeiro, uma vez que admite a possibilidade de desrespeito às leis orçamentárias e, se há referência à pena, é porque se aceita a ideia de crime, embora a própria pena de perda do mandato seja questionada. O impeachment seria uma sanção muito dura para um crime que tantos outros cometeram sem que lhes fosse aplicado qualquer tipo de punição.

Nas brechas da linguagem: considerações finais

O ponto de tensão presente nas duas reportagens dizem respeito, sobretudo, ao uso da linguagem que reflete as formações discursivas e ideológicas das quais os sujeitos estão inseridos. A tensão se dá no jogo da linguagem, nos sentidos produzidos e nas identificações demandadas. É nesse jogo que a AD se estabelece como possibilidade de leitura das realidades, e esse olhar sensível permitido pela AD é possível em função das interlocuções de autores como Foucault, Pêcheux e Orlandi, estes nos estimulam a perceber que as palavras não contêm sentido em si mesmas, são as $\mathrm{CP}$, as formações discursivas-ideológicas e as posições de sujeito que investem de sentido às palavras. Dessa forma, sujeito e sentido se constituem mutuamente na produção de sentido, segundo a AD. 
EID\&A - Revista Eletrônica de Estudos Integrados em Discurso e Argumentação, Ilhéus, n. 12, jul/dez.2016.

É possível observar por meio das análises que a linguagem não é transparente, objetiva e autoexplicativa. A linguagem está na fronteira, no cruzamento, no entre-lugar do dito e não dito, das intenções que refletem as ideologias, reflete também vontades, desejos, posicionamentos. É por meio da linguagem que os argumentos são desenvolvidos e os interlocutores são envolvidos nas ideologias dominantes ou não. É na/pela linguagem que os efeitos de sentido vão sendo construídos e reconstruídos, num jogo de mostrar e esconder para persuadir.

As diversas formas de linguagens são tão importantes que as mídias jornalísticas, os jornais televisionados, impressos, virtuais, as rádios, as revistas podem contribuir de forma incisiva na eleição de um candidato a presidente da República, como também podem manipular as informações a ponto de provocar uma mobilização social que clame pelo seu impedimento. É possível criar manobras políticas por meio de textos que conduzam o interlocutor a se posicionar contra ou a favor de um acontecimento.

A partir da linguagem, é possível observar as posições sociais dos indivíduos, bem como dos grupos dos que fazem parte. A adjetivação dos grupos que são contrários à permanência da presidente no governo são negativas, depreciativas da figura de Dilma Rousseff, o que no jogo linguístico e político eleva positivamente a figura do seu vice-presidente Michel Temer. Dessa forma, as textualizações indicam que a linguagem não é transparente, objetiva e muito menos neutra, pelo contrário é notadamente ideológica. É ainda é possível notar a porosidade da linguagem nos usos dos termos como golpe, crime, impeachment e lei. Os discursos são, assim, cheios de atravessamentos de outros discursos que apenas se estabilizam por um intervalo de tempo, tempo necessário para que novas/outras CP apareçam e outros discursos tomem corpo. Os enunciados constantes no jornal indicam de que posição, ideologia e formação discursiva os sujeitos falam.

As representações construídas pelo jornal acerca das pedaladas fiscais criam, em sua maioria, a ideia de crime de responsabilidade fiscal, favorecem a emergência, a partir dos textos publicados, de uma atmosfera social de mudança, de justiça e transformação. Existem, no conjunto de textos organizados, reportagens mais reflexivas, mais ponderadas a respeito das pedaladas fiscais e do afastamento da presidente, mas essas não são maioria e muitas vezes ficam ofuscadas pelas reportagens que têm uma linguagem de 
EID\&A - Revista Eletrônica de Estudos Integrados em Discurso e Argumentação, Ilhéus, n. 12, jul/dez.2016.

alto impacto, como a analisada no subitem anterior: "Dilma planejou milimetricamente seus crimes de responsabilidade".

\section{Referências}

BRANDÃO, Helena H. N. Introdução à análise do discurso. 3. ed. Campinas: Editora da Unicamp, 2012.

COURTINE, Jean-Jacques. Análise do discurso político: o discurso comunista endereçado aos cristãos. São Carlos: Edufscar, 2009. p. 45-68.

FOUCAULT, Michel. Retornar à História. In: - Arqueologia das ciências e história dos sistemas de pensamento. Trad. Elise Monteiro. Rio de Janeiro: Forense Universitária, 2005. Coleção Ditos e escritos Vol. Il. p. 282-295.

MAINGUENEAU, Dominique. Discurso e análise do discurso. Trad. Sírio Possenti. São Paulo. Parábola Editorial, 2015.

MALDIDIER, Denise. A inquietação do discurso: (Re)Ler Michel Pêcheux hoje. Trad. de Eni P. Orlandi. Campinas: Pontes Editores, 2003.

MARTINS, Luísa; PORTO, Gustavo. Dilma planejou milimetricamente seus crimes de responsabilidade. O Estado de São Paulo, São Paulo, 11 mai. 2016. Disponível em: <http://politica.estadao.com.br/noticias/geral,dilma-planejou-milimetricamente-seuscrimes-de-responsabilidade--diz-eduardo-amorim,10000050548>. Acesso em: 11 mai. 2016.

ORLANDI, Eni P. Análise de discurso: princípios e procedimentos. 12. ed. Campinas: Pontes Editores, 2015.

Editores, 2001.

. Discurso e texto: formulação e circulação dos sentidos. Campinas: Pontes

. Interpretação: autoria, leitura e efeitos do trabalho simbólico. Petrópolis: Vozes, 1996.

PÊCHEUX, Michel; FUCHS, Catherine. A propósito da análise automática do discurso: atualização e perspectivas. In: GADET, Françoise; HAK, Tony (Org.). Por uma análise automática do discurso. Uma introdução à obra de Michel Pêcheux. 3. ed. Trad. Bethania S. Mariani. Campinas: Editora da Unicamp, 1997. p.163-252. 
EID\&A - Revista Eletrônica de Estudos Integrados em Discurso e Argumentação, Ilhéus, n. 12, jul/dez.2016.

PÊCHEUX, Michel; HAROCHE, Claudine; HENRY, Paul. A semântica e o corte saussuriano: língua, linguagem e discurso. In: BARONAS, Roberto Leiser. Análise de discurso: apontamentos para uma história da noção-conceito de formação discursiva. São Carlos: Pedro \& João Editores, 2011. p. 13-32.

POSSENTI, Sírio. Os limites do discurso: ensaios sobre discurso e sujeito. São Paulo: Parábola Editorial, 2009.

ROMÃO, Wagner. Instituições democráticas perdem para democracia da maioria. 0 Estado de São Paulo, São Paulo, 12 mai. 2016. Disponível em: <http://politica.estadao.com.br/noticias/geral,dilma-planejou-milimetricamente-seuscrimes-de-responsabilidade--diz-eduardo-amorim,10000050548>. Acesso em: 12 mai. 2016.

Forma de citação sugerida:

AZEVEDO, Livia Dias de. Pedaladas fiscais: discursos do jornal O Estado de São Paulo. EID\&A - Revista Eletrônica de Estudos Integrados em Discurso e Argumentação, Ilhéus, n. 12, p. 135-153, jul/dez.2016.

Recebido em: 21/07/2016

Aprovado em: 30/11/2016 